\title{
Human apoA-l increases macrophage foam cell derived PLTP activity without affecting the PLTP mass
}

\author{
Marius R Robciuc*1, Jari Metso ${ }^{1}$, Anca Sima2 ${ }^{2}$ Christian Ehnholm¹ and Matti Jauhiainen¹
}

\begin{abstract}
Background: phospholipid transfer protein (PLTP) plays important roles in lipoprotein metabolism and atherosclerosis and is expressed by macrophages and macrophage foam cells (MFCs). The aim of the present study was to determine whether the major protein from HDL, apoA-I, affects PLTP derived from MFCs.

Results: as cell model we used human THP-1 monocytes incubated with acetylated LDL, to generate MFC. The addition of apoA-I to the cell media increased apoE secretion from the cells, in a concentration dependent fashion, without affecting cellular apoE levels. In contrast, apoA-I had no effect on PLTP synthesis and secretion, but strongly induced the PLTP activity in the media. ApoA-I also increased phospholipid transfer activity of PLTP isolated from human plasma. This effect was dependent on apoA-I concentration but independent on apoA-I lipidation status. ApoE, ApoA-II and apoA-IV, but not immunoglobulins or bovine serum albumin, also increased PLTP activity. We also report that apoA-I protects PLTP from heat inactivation.
\end{abstract}

Conclusion: apoA-I enhances the phospholipid transfer activity of PLTP secreted from macrophage foam cells without affecting the PLTP mass.

\section{Background}

Atherosclerosis is an inflammatory disorder in the artery wall caused by the accumulation of atherogenic lipoproteins such as low density lipoproteins (LDL) and triglyceride rich remnant lipoproteins. In the artery wall these lipoproteins are modified and taken up by macrophages. This sterol loading of the macrophages promotes the formation of macrophage foam cells (MFCs) essential constituents of human atherosclerotic lesions [1]. Currently, major efforts are made to develop therapies that will promote removal of cholesterol from lesion foam cells and lead to regression of the atherosclerotic process [2]. Animal studies have shown that high density lipoproteins (HDL) can promote the removal of cholesterol from the arterial wall and transport it to the liver for excretion in a process called reverse cholesterol transport (RCT) [3]. In addition to RCT, HDL also has several other protective

\footnotetext{
* Correspondence: marius.robciuc@thl.fi

${ }^{1}$ National Institute for Health and Welfare, Public Health Genomics Research Unit and FIMM, Institute for Molecular Medicine Finland, Haartmaninkatu 8, Biomedicum, Helsinki, Finland

Full list of author information is available at the end of the article
}

functions such as antioxidant, antiinflammatory, vasodilating and antithrombotic properties that contribute to the strong independent inverse relationship with atherosclerotic cardiovascular disease [3].

Phospholipid transfer protein (PLTP) is expressed by macrophages and the expression levels are increased in MFCs due to LXR activation [4-6]. Bone marrow transplantation studies in mice using PLTP deficient macrophages gave conflicting results, and this treatment either decreased [7] or increased atherosclerosis [8]. Mechanisms by which macrophage PLTP may be protective in atherogenesis involves the stabilization of ATPbinding cassette transporter A1 (ABCA1) and stimulation of cholesterol efflux $[9,10]$, however, a recent study suggests that elevation of PLTP in macrophage does not affect RCT [11]. Furthermore, PLTP expression by macrophages results in atherogenic effects on plasma lipids and increased atherosclerotic lesion size [12].

Interestingly, it was shown that HDL levels are an important determinant of PLTP levels and it was further suggested that HDL might play a role in the stabilization of PLTP $[13,14]$. To date, no detailed studies addressing 
the effect of apoA-I on PLTP expression and secretion from human macrophages have been reported.

In the present study we have investigated the effect of exogenous human apoA-I on the synthesis and secretion of PLTP from human macrophage foam cells.

\section{Methods}

Cell culture, lipid loading and pharmacological treatments

Human THP-1 monocytes were purchased from the American Type Culture Collection (ATCC, Manassas, VA). The monocytes were grown and maintained in RPMI 1640 medium containing 10\% (v/v) FBS, $10 \mathrm{mM}$ Hepes, $\mathrm{pH} 7.4,100 \mathrm{U} / \mathrm{mL}$ penicillin, and $100 \mu \mathrm{g} / \mathrm{mL}$ streptomycin at $37^{\circ} \mathrm{C}$ under $5 \% \mathrm{CO}_{2}$ in a humidified incubator. To differentiate the monocytes into macrophages, the cells were plated onto 24-well plates and treated with $100 \mathrm{nM}$ phorbol 12-myristate 13-acetate (PMA) (SigmaAldrich, St. Louis, MO) in the growth medium for $72 \mathrm{~h}$ prior to the experiment. The macrophages were loaded by incubating them in the presence of $25 \mu \mathrm{g}$ of protein/ well of acetylated LDL (AcLDL) in RPMI 1640 supplemented with $5 \%(\mathrm{v} / \mathrm{v})$ fetal bovine lipoprotein deficient serum (LPDS), $10 \mathrm{mM}$ Hepes, $\mathrm{pH}$ 7.4, and penicillin/ streptomycin for $48 \mathrm{~h}$. ApoE protein and PLTP mRNA, protein and activity levels were assessed $24 \mathrm{~h}$ after incubation in the presence or absence of apoA-I. The viability and attachment of the cells were carefully evaluated by light microscopy and protein measurements and no cytotoxic effects could be observed.

\section{SDS-PAGE and Immunoblot Analysis}

Equivalent amounts of protein from the cell lysate and medium were subjected to Western blot analysis. Medium was concentrated 50-fold for the detection of apoE and PLTP. To detect apoE we used a monoclonal antibody raised against the human apoE or a horseradish peroxidase (HRP)-conjugated polyclonal antibody specific for human apoE (DAKO, Denmark). For PLTP detection we used a mouse monoclonal antibody (Mab59) or a rabbit polyclonal antibody raised against purified human plasma PLTP. Cellular actin was detected using a specific rabbit polyclonal antibody (Santa Cruz).

\section{ApoE ELISA}

Human apoE was detected by ELISA as described previously [15] with some modifications. Briefly, we used a polyclonal rabbit antibody (R107) as a capture antibody to coat 96-well plates. As a detection antibody we used a HRP-conjugated polyclonal antibody specific for human apoE (DAKO, Denmark). Standard curve was prepared using a standardized serum (Daichi, Japan).

\section{Gene expression analyses}

PLTP mRNA levels were measured by real time PCR using as forward primer 5'-ACGCAGGGACGGTCCT-
GCTC-3' and as reverse primer 5'-CTCATTGAGCATGGGCATCACCCC-3' [5]. Cultured cells were homogenized in RLT buffer (Qiagen, Valencia, CA) and total RNA was isolated with RNeasy Mini kit (Qiagen) according to the manufacturer's instructions. The total RNA $(2 \mu \mathrm{g})$ was reverse-transcribed by using Superscript II (Invitrogen, Carlsbad, CA) and random hexamer primers (Applied Biosystems, Foster City, CA). Samples were amplified in triplicate for PLTP and two housekeeping genes, GAPDH and 18S rRNA, on a 7000 Sequence Detection System (Applied Biosystems), using a SYBRgreen kit (Applied Biosystems).

\section{Purification of PLTP from human plasma}

PLTP was purified from human plasma according to Marques-Vidal et al. [16]. Briefly, the human plasma fractions, eluted from Butyl-Toyopearl 650(M) column, containing PLTP activity were combined and applied to a first heparin-sepharose column. After extensive washing with the equilibration buffer, PLTP activity was eluted with $25 \mathrm{mM}$ Tris- $\mathrm{HCl}$ buffer, $\mathrm{pH}$ 7.40, containing $1 \mathrm{mM}$ EDTA and $1.0 \mathrm{M} \mathrm{NaCl}$. The fractions containing PLTP activity were combined, dialysed against $25 \mathrm{mM}$ Tris- $\mathrm{HCl}$ buffer, $\mathrm{pH}=7.40$, containing $1 \mathrm{mM}$ EDTA, and applied to a Mono Q HR 5/5 column, attached to a Merck HPLC system. The column was eluted with a linear $\mathrm{NaCl}$ gradient (0-0.5 M) prepared in equilibration buffer. The fractions containing PLTP activity were combined, dialysed against $25 \mathrm{mM}$ Tris- $\mathrm{HCl}$ buffer, $\mathrm{pH} 7.40$, containing 1 mM EDTA and then applied on a second heparin-sepharose column (Hi-Trap, $1 \mathrm{ml}$ total volume, Pharmacia, Upsala, Sweden). The column was then eluted with a linear $\mathrm{NaCl}$ gradient $(0-0.5 \mathrm{M})$. Active fractions from the Hi-Trap column were pooled and applied to a hydroxylapatite column ( $2 \mathrm{ml}$ total volume) previously equilibrated with $1 \mathrm{mM}$ Na-phosphate buffer, $\mathrm{pH}$ 6.80, containing $150 \mathrm{mM} \mathrm{NaCl}$. PLTP was eluted with a linear Na-phosphate gradient (1-500 mM). PLTP activity eluted at a phosphate concentration of 125-150 mM. PTLP activity ranged between 2000 and $6000 \mathrm{nmol}$ phospholipid transferred $/ \mathrm{h} / \mathrm{ml}$ depending on the preparation and was devoid of H-TGL, LCAT, phospholipase and CETP activity.

\section{PLTP activity}

PLTP activity was measured using a radiometric method as previously described [17]. Cholesterol loaded macrophage media was 5 -fold concentrated by ultrafiltration and washed twice with PLTP activity assay buffer before the activity was measured.

\section{ApoA-I lipidation}

For apoA-I lipidation we used increasing amounts of $\mathrm{L}-\alpha$ Phosphatidylcholine (Sigma-Aldrich, St. Louis, MO). The molar ratio of the proteoliposomes, apoA-I:PC:CHOL, 
was as follow: 1:50:0, 1:50:7, 1:100:0, 1:100:7, 1:150:0 and 1:150:7. PC and CHOL were dried under nitrogen at room temperature in glass tubes and resuspended in the assay buffer $(10 \mathrm{mM}$ Tris- $\mathrm{HCl}, 1 \mathrm{mM}$ EDTA, $140 \mathrm{mM}$ $\mathrm{NaCl}, \mathrm{pH}$ 7.4). ApoA-I was added to the mixture at a concentration of $1 \mathrm{mg} / \mathrm{ml}$. After the addition of Na-cholate the samples were mixed gently avoiding foaming followed by 20 minutes incubation at $24^{\circ} \mathrm{C}$ in a water bath with gentle shaking. Finally the samples were dialyzed against assay buffer for 20-40 hours and stored at $+4^{\circ} \mathrm{C}$.

\section{Results}

Loading of THP-1 macrophages with AcLDL resulted in an increase in apoE, PLTP and cholesteryl-ester transfer protein (CETP) secretion (data not shown). When ApoAI was added to the media of cholesterol loaded macrophages (Figure 1) the apoE secretion was increased. ApoA-I addition did not affect the cellular content of apoE (Figure 1, panel A and B). ApoE secretion from the cells was measured by a specific ELISA in serum free media containing 10, 20, 40 and $80 \mu \mathrm{g} / \mathrm{ml}$ apoA-I and a

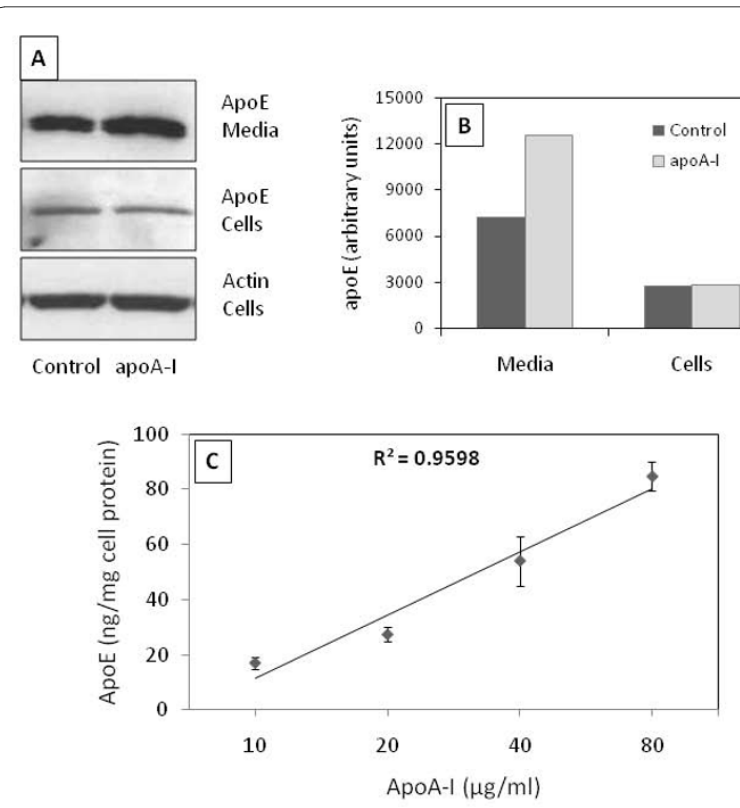

Figure 1 Induction of apoE secretion by apoA-l in macrophage foam cells (MFCs). Panel A, apoE was analyzed by Western blot in the media and cellular lysate from lipid loaded macrophages incubated in the presence of $10 \mu \mathrm{g} / \mathrm{ml}$ apoA-I (apoA-l) or without (Control) for 24h. Panel B, bands were quantified (Image J v1.42q software) and the bars represent the intensity of apoE bands normalized to intensity of actin band. Panel C, increasing concentrations of apoA-I were added in the culture media of MFC and apoE concentration was quantified after $3 \mathrm{~h}$ of incubation. ApoE concentration was determined by ELISA and values were normalized to total cell protein concentration. A linear relationship between apoA-I and apoE concentration was observed $\left(R^{2}=\right.$ 0.959). The dots and error bars represent the mean \pm SD calculated from triplicates. The results are representative for at least 3 independent experiments. concentration dependent induction in the secretion (up to 5 -fold) could be observed (Figure 1, panel C).

The stimulating effect of apoA-I on apoE secretion from macrophages has been reported by several groups and also confirmed by us in the present study. We further investigated whether apoA-I also affects PLTP secretion from macrophages, as both, PLTP and apoE, are known to be important players in macrophage cholesterol homeostasis and are associated with HDL or apoA-I [18]. Moreover, PLTP deletion from macrophages reduces apoE secretion [19] suggesting that PLTP could play a role in the apoA-I induced apoE secretion. Real time PCR quantification showed no effect of apoA-I on PLTP mRNA levels whereas all-trans retinoic acid (ATRA), agonist for Retinoic X Receptor (RXR), induced a 3.5-fold increase in the relative PLTP mRNA expression (Figure 2, panel A). Western blot analysis revealed that, there was no apoA-I mediated effect on cellular levels of PLTP and, in contrast to apoE, also in the media PLTP levels remained similar after the apoA-I addition (Figure 2, panel B). In contrast, addition of an LXR agonist (22-OH cholesterol) markedly increased PLTP secretion from the cells (data not shown). PLTP activity in the media was 3fold increased by the addition of $10 \mu \mathrm{g} / \mathrm{ml}$ apoA-I,

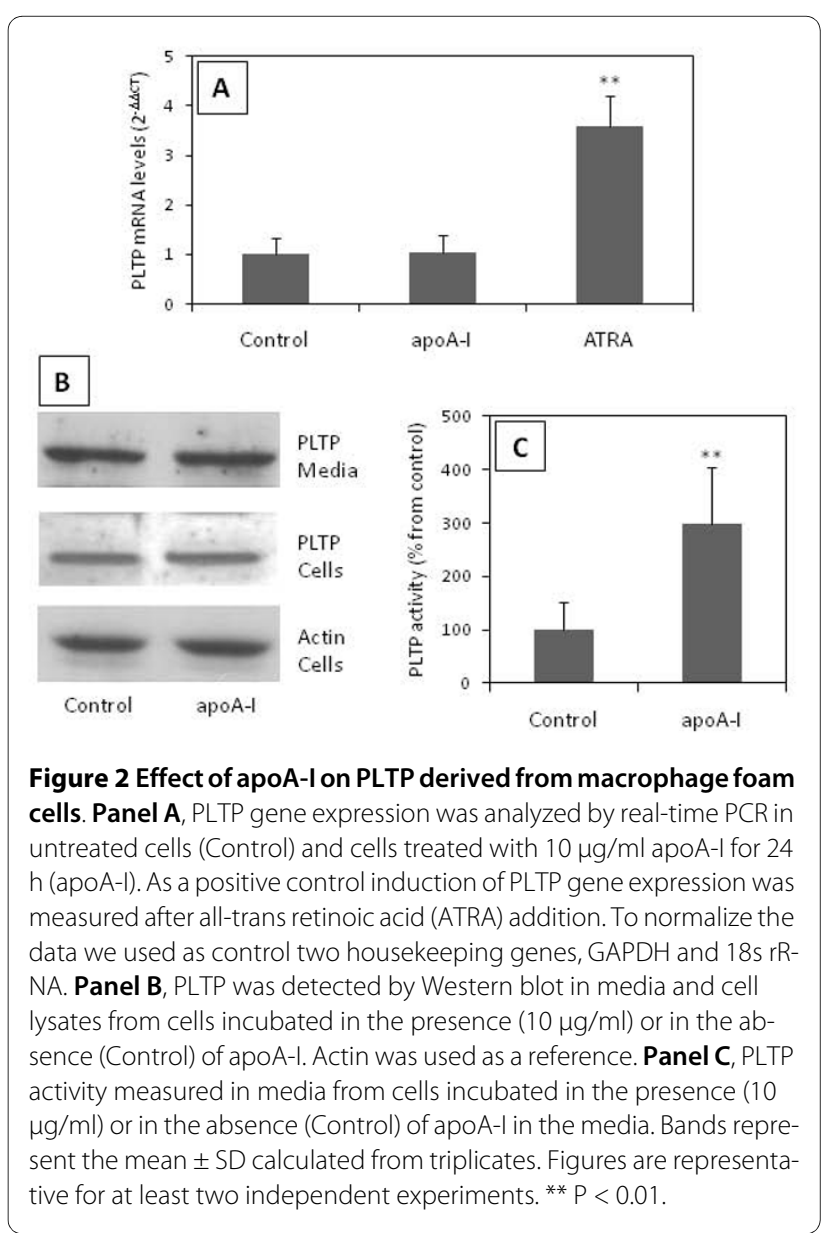


although apoA-I had no effect on PLTP protein levels in cell culture media (Figure 2, panel C).

Because the macrophage media also contains apoE that presumably could mediate the apoA-I induction of PLTP activity we also performed experiments where only purified human plasma PLTP and lipid free apoA-I were coincubated. ApoA-I significantly induced purified PLTP activity in a concentration dependent manner (Figure 3, panel A). To exclude the possibility that the effect observed on PLTP activity could be due to the addition of lipid free apoA-I in the PLTP assay reaction mixture, we evaluated the phospholipid transfer of apoA-I in the absence of PLTP. No phospholipid transfer could be detected with $50 \mu \mathrm{g}$ apoA-I, 4-fold higher than the highest amount of apoA-I used with PLTP (Figure 3, panel A). The apoA-I mediated induction of purified PLTP activity was abolished by a specific anti-apoA-I polyclonal antibody whereas the non-specific antibody had no effect on the activity (Figure 3, panel B).
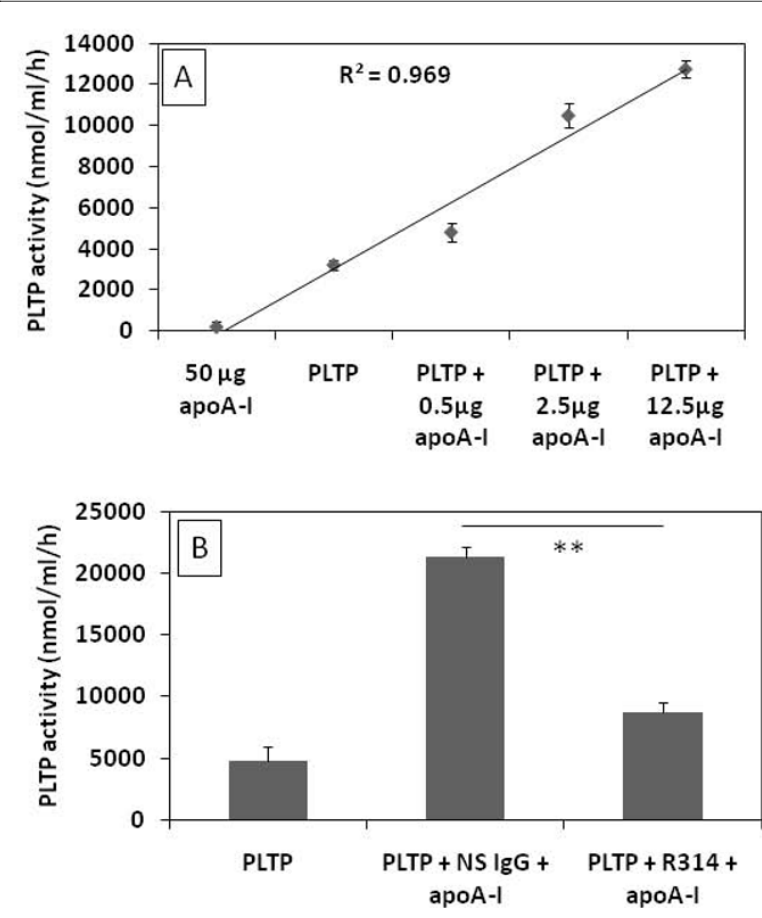

Figure 3 Effect of apoA-I on the activity human purified PLTP. Panel A, PLTP isolated from human plasma was pre-incubated for 2 hours at room temperature in the presence of increasing concentrations of apoA-I and thereafter assayed for phospholipid transfer activity. As a control, $50 \mu \mathrm{g}$ apoA-I were added to the reaction mixture in the absence of PLTP. A linear relationship between apoA-I concentration and PLTP activity was observed $\left(R^{2}=0.969\right)$. Dots and error bars represent mean \pm SD calculated from triplicates. Panel B, apoA-I was pre-incubated with non-specific rabbit polyclonal antibodies (NS IgG) and anti-apoA-I rabbit polyclonal antibodies (R314) and the effects on PLTP activity were evaluated. Figures are representative for three independent experiments. Bars and error bars represent mean \pm SD calculated from triplicates. ${ }^{* *} \mathrm{P}<0.01$.
We have further questioned whether the observed effect of apoA-I on PLTP activity depends on the apoA-I lipidation or whether it is restricted to apoA-I only. To answer the first question, we have lipidated apoA-I with increasing amounts of $\mathrm{PC}$, as described in material and methods. As depicted in figure 4 (panel A), increased apoA-I lipidation did not have a significant effect on the observed induction of PLTP activity. In addition, HDL isolated from human plasma was equally effective in inducing the PLTP activity. Furthermore, we also showed that lipid-free apoA-II, apoA-IV and apoE induced purified PLTP activity to a similar extent as apoA-I (Figure 4, panel B). In contrast, proteins not belonging to the apolipoprotein family of proteins such as rabbit non-specific immunoglobulins and bovine serum albumin had no significant effect on PLTP activity (Figure 4, panel B).

Plasma purified PLTP can be inactivated by heating at $56^{\circ} \mathrm{C}$ for one hour (Figure 5) [20]. To test if apoA-I can protect PLTP from heat inactivation, we preincubated purified PLTP from plasma with $20 \mu \mathrm{g}$ apoA-I. Preincubation of PLTP with apoA-I preserved the phospholipid transfer activity, but the addition of apoA-I after heat

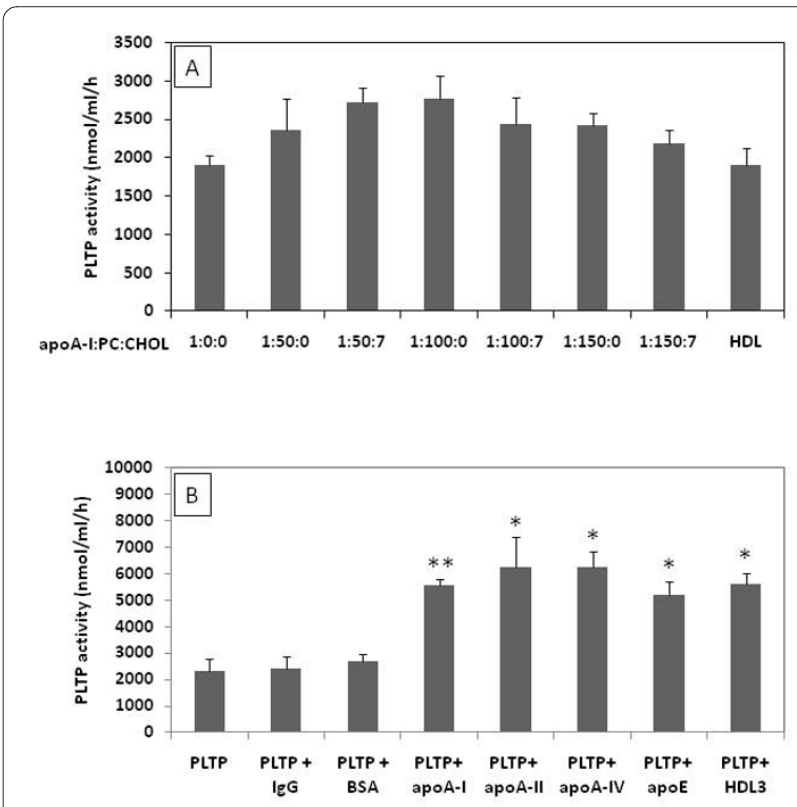

Figure 4 The capacity of lipidated apoA-I and other apolipoproteins to induce PLTP activity. Panel A, PLTP was incubated for 2 hours at room temperature in the presence of $10 \mu \mathrm{g} / \mathrm{ml}$ of lipid free apoA-I or lipidated with increasing amounts of phosphatidylcholine (PC) and cholesterol (CHOL) and $10 \mu \mathrm{g} / \mathrm{ml} \mathrm{HDL}$ (representing a highly lipidated form of apoA-l) and assayed for the phospholipid transfer activity. Panel B, PLTP was incubated for 2 hours at room temperature in the presence of $10 \mu \mathrm{g} / \mathrm{ml}$ of purified rabbit imunoglobulins (lgG), bovine serum albumin (BSA), apoA-I, apoA-II, apoA-IV, apoE and HDL and analyzed for phospholipid transfer activity. Figures are representative for three independent experiments. Bars and error bars represent mean \pm SD calculated from triplicates. ${ }^{*} P<0.05,{ }^{*} P<0.01$ 


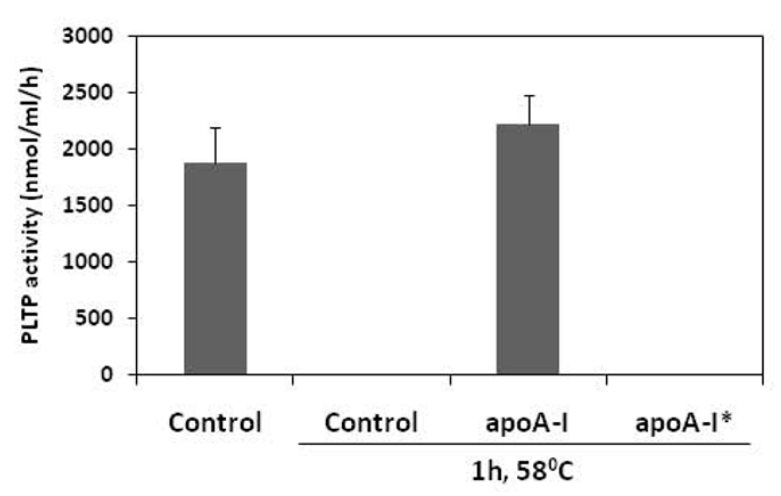

Figure 5 Stabilizing effect of apoA-I on PLTP activity. PLTP was incubated at $58^{\circ} \mathrm{C}$ for 1 hour in the presence or absence of $20 \mu \mathrm{g}$ apoA-I and assayed for the phospholipid transfer activity. Figure is representative for two independent experiments performed with two different PLTP batches. Bars represent mean \pm SD calculated from duplicates. *20 $\mu \mathrm{g}$ apoA-I was added to PLTP after the incubation at $58^{\circ} \mathrm{C}$ for 1 hour.

inactivation of PLTP failed to recover the lost phospholipid transfer activity (Figure 5). This shows that apoA-I not only enhanced phospholipid transfer protein activity of PLTP but has also a stabilizing effect.

Finally, because apoA-I enhances both PLTP activity and apoE secretion from MFC we questioned whether apoA-I mediate its effect on apoE secretion by enhancing the PLTP activity. To test this we added plasma purified PLTP in the media of MFC and evaluated the apoE secretion using ELISA. As depicted in figure 6, addition of PLTP $(200 \mathrm{nmol} / \mathrm{ml} / \mathrm{h}$ ) was equally ineffective in stimulating apoE secretion from MFC as the addition of bovine serum albumin.

\section{Discussions}

PLTP synthesized by macrophage and MFCs has been associated with the development of atherosclerosis. In

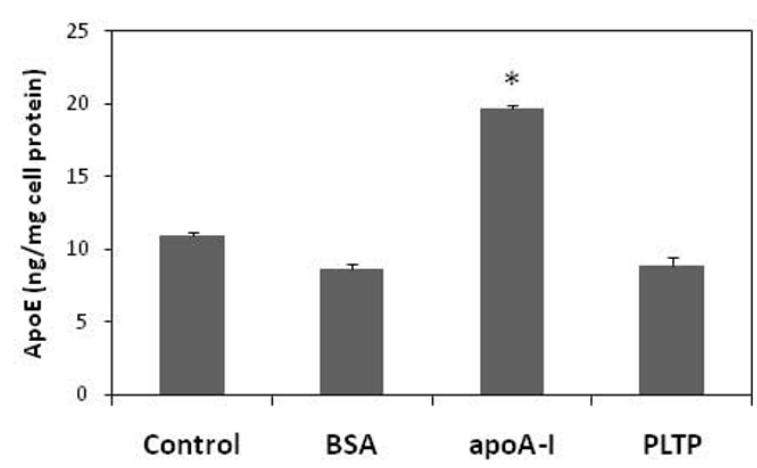

Figure 6 Effect of PLTP on apoE secretion. ApoE was analyzed by ELISA in the media from MFC incubated with $10 \mu \mathrm{g} / \mathrm{ml}$ bovine serum albumin (BSA), $10 \mathrm{\mu g} / \mathrm{ml}$ apoA-I (apoA-l) or with $200 \mathrm{nmol} / \mathrm{ml} / \mathrm{h}$ PLTP for $24 \mathrm{~h}$. Figure is representative for two independent experiments. Bars represent mean \pm SD calculated from triplicates. ${ }^{*} \mathrm{P}<0.05$. the current study we investigated the effect of apoA-I on PLTP secreted from MFC.

Our results confirm existing data which show that apoA-I strongly stimulates apoE secretion from macrophages, an effect that is likely to contribute to the antiatherogenic potential of HDL. Interestingly, the enhancement of apoE secretion induced by apoA-I is concentration dependent, but even at levels as high as 80 $\mu \mathrm{g} / \mathrm{ml}$ a saturation of the system could not be demonstrated. This suggests that the system capacity is very high and can have important consequences in MFCs physiology as well as in plasma lipoprotein metabolism.

PLTP secreted by macrophages contributes significantly to total plasma phospholipid transfer activity [7]. The plasma PLTP pool derived from macrophages has most probably a major impact on plasma lipoprotein metabolism and atherogenesis. In the present study we demonstrate that apoA-I does not affect PLTP secretion from macrophages but instead increases PLTP facilitated phospholipid transfer activity. The induction of phospholipid transfer is due to a direct effect of apoA-I on PLTP since the incubation of purified PLTP in the presence of apoA-I resulted in an effect similar to that observed with macrophage derived PLTP. These in vitro observations suggest that this effect most probably is valid for PLTP secreted from other tissues. Indeed, the PLTP activity in $A B C A 1$ deficiency, that results in very low levels of apoAI and HDL in plasma, is significantly reduced $[13,14]$. The effect we report here is specific not only for apoA-I since an increase of PLTP activity was also observed following incubation in the presence of other apolipoproteins such as apoA-II, apoA-IV and apoE. This suggests that PLTP requires interactions with proteins containing amphipathic $\alpha$-helix domains for proper lipid transfer activity. Interestingly, similar structural characteristics are needed for the induction of apoE secretion from macrophages [21].

It is well known that PLTP is associated in plasma with HDL [22] and the particles containing PLTP are highly variable regarding the phospholipid transfer capacity [23]. It is not clear yet what is the determining factor for the differences in the PLTP activity and this remains to be established [24,25]. Although the interaction of PLTP with lipoprotein surfaces is an obligatory component of lipid transfer, so far, it was not clearly demonstrated that apoA-I and HDL can actually enhance PLTP activity.

It was recently reported that macrophage PLTP deficiency causes a significant reduction of apoE secretion in vivo [19]. The mechanism behind this observation is not known but it may involve the stabilizing effect of PLTP on $A B C A 1$, known to be responsible for basal apoE secretion [21]. A second possibility is that PLTP could mediate HDL induced secretion of apoE from macrophages. Our observations, that apoA-I does not affect the synthesis and secretion of PLTP from macrophages and that 
increased PLTP activity in macrophage media, by addition of exogenous active PLTP, do not increase apoE secretion from macrophages, are indirect evidence that the first hypothesis is more likely.

\section{Conclusions}

In summary, we have demonstrated that, in cholesterol loaded macrophages, apoA-I does not affect PLTP synthesis or secretion but increases PLTP mediated phospholipid transfer activity. The same was observed with purified plasma PLTP and the effect was independent on apoA-I lipidation status and could be demonstrated by other proteins containing amphipathic $\alpha$-helix domains. We also provide evidence that the apoA-I induced apoE secretion from macrophages and the enhancement of PLTP activity by apoA-I are unrelated phenomena.

\section{Competing interests}

The authors declare that they have no competing interests.

\section{Authors' contributions}

MRR conceived and designed the study, carried out the majority of the experiments and wrote the manuscript. JM, carried out PLTP activity assays and help with the experimental design for in vitro studies. AS, participated in the study design and coordination, and revised the manuscript for important intellectual content. $\mathbf{C E}$, participated in the design of the study and revised the manuscript for important intellectual content. $\mathbf{M J}$, coordinated the study, made substantial contributions to its conception and design and revised the manuscript for important intellectual content.

All authors read and approved the manuscript.

\section{Acknowledgements}

The authors would like to express gratitude to Acad. Maya Simionescu for facilitating this collaborative study and Sari Nuutinen for excellent technical assistance. This study was supported by the Research Council for the Health, Academy of Finland, Grants 114484 and 132629, Ministry for Education, Research, Youth and Sport, Romania, Grant 1220/2008, Finska Läkaresällskape and Magnus Ehrnrooth Foundation.

\section{Author Details}

${ }^{1}$ National Institute for Health and Welfare, Public Health Genomics Research Unit and FIMM, Institute for Molecular Medicine Finland, Haartmaninkatu 8, Biomedicum, Helsinki, Finland and Institute of Cellular Biology and Pathology "Nicolae Simionescu", B. P. Hasdeu 8, Bucharest, Romania

Received: 5 May 2010 Accepted: 9 June 2010

Published: 9 June 2010

\section{References}

1. Rocha VZ, Libby P: Obesity, inflammation, and atherosclerosis. Nat Rev Cardio/ 2009, 6(6):399-409.

2. Duffy D, Rader DJ: Update on strategies to increase HDL quantity and function. Nat Rev Cardiol 2009, 6(7):455-463.

3. Escola-Gil JC, Rotllan N, Julve J, Blanco-Vaca F: In vivo macrophagespecific RCT and antioxidant and antiinflammatory HDL activity measurements: New tools for predicting HDL atheroprotection. Atherosclerosis 2009, 206(2):321-327.

4. Laffitte BA, Joseph SB, Chen M, Castrillo A, Repa J, Wilpitz D, Mangelsdorf $\mathrm{D}$, Tontonoz $\mathrm{P}$ : The phospholipid transfer protein gene is a liver $\mathrm{X}$ receptor target expressed by macrophages in atherosclerotic lesions. Mol Cell Biol 2003, 23(6):2182-2191.

5. Desrumaux CM, Mak PA, Boisvert WA, Masson D, Stupack D, Jauhiainen M, Ehnholm C, Curtiss LK: Phospholipid transfer protein is present in human atherosclerotic lesions and is expressed by macrophages and foam cells. J Lipid Res 2003, 44(8):1453-1461.
6. O'Brien KD, Vuletic S, McDonald TO, Wolfbauer G, Lewis K, Tu AY Marcovina S, Wight TN, Chait A, Albers JJ: Cell-associated and extracellular phospholipid transfer protein in human coronary atherosclerosis. Circulation 2003, 108(3):270-274.

7. Vikstedt R, Ye D, Metso J, Hildebrand RB, Van Berkel TJ, Ehnholm C, Jauhiainen M, Van Eck M: Macrophage phospholipid transfer protein contributes significantly to total plasma phospholipid transfer activity and its deficiency leads to diminished atherosclerotic lesion development. Arterioscler Thromb Vasc Biol 2007, 27(3):578-586.

8. Valenta DT, Ogier N, Bradshaw G, Black AS, Bonnet DJ, Lagrost L, Curtiss LK, Desrumaux CM: Atheroprotective potential of macrophage-derived phospholipid transfer protein in low-density lipoprotein receptordeficient mice is overcome by apolipoprotein Al overexpression. Arterioscler Thromb Vasc Biol 2006, 26(7):1572-1578.

9. Oram JF, Wolfbauer G, Vaughan AM, Tang C, Albers JJ: Phospholipid transfer protein interacts with and stabilizes ATP-binding cassette transporter $\mathrm{A} 1$ and enhances cholesterol efflux from cells. J Biol Chem 2003, 278(52):52379-52385.

10. Lee-Rueckert M, Vikstedt R, Metso J, Ehnholm C, Kovanen PT, Jauhiainen $M$ : Absence of endogenous phospholipid transfer protein impairs ABCA1-dependent efflux of cholesterol from macrophage foam cells. J Lipid Res 2006, 47(8):1725-1732.

11. Samyn H, Moerland M, van Gent T, van Haperen R, Grosveld F, van Tol A, de Crom R: Elevation of systemic PLTP, but not macrophage-PLTP, impairs macrophage reverse cholesterol transport in transgenic mice. Atherosclerosis 2009, 204(2):429-434.

12. van Haperen R, Samyn H, Moerland M, van Gent T, Peeters M, Grosveld F, van Tol A, de Crom R: Elevated expression of phospholipid transfer protein in bone marrow derived cells causes atherosclerosis. PLoS One 2008, 3(5):e2255.

13. Oka T, Yamashita S, Kujiraoka T, Ito M, Nagano M, Sagehashi $Y$, Egashira $T$, Nanjee MN, Hirano K, Miller NE, et al:: Distribution of human plasma PLTP mass and activity in hypo- and hyperalphalipoproteinemia. J Lipid Res 2002, 43(8):1236-1243.

14. Samyn H, Moerland M, van Gent T, van Haperen R, van Tol A, de Crom R: Reduction of HDL levels lowers plasma PLTP and affects its distribution among lipoproteins in mice. Biochim Biophys Acta 2009, 1791(8):790-796.

15. Siggins S, Jauhiainen M, Olkkonen VM, Tenhunen J, Ehnholm C: PLTP secreted by HepG2 cells resembles the high-activity PLTP form in human plasma. J Lipid Res 2003, 44(9):1698-1704.

16. Marques-Vidal $P$, Jauhiainen M, Metso J, Ehnholm C: Transformation of high density lipoprotein 2 particles by hepatic lipase and phospholipid transfer protein. Atherosclerosis 1997, 133(1):87-95.

17. Jauhiainen M, Ehnholm C: Determination of human plasma phospholipid transfer protein mass and activity. Methods 2005, 36(2):97-101.

18. Pussinen PJ, Jauhiainen M, Metso J, Pyle LE, Marcel YL, Fidge NH, Ehnholm C: Binding of phospholipid transfer protein (PLTP) to apolipoproteins A-I and A-II: location of a PLTP binding domain in the amino terminal region of apoA-I. J Lipid Res 1998, 39(1):152-161.

19. Liu R, Hojjati MR, Devlin CM, Hansen IH, Jiang XC: Macrophage phospholipid transfer protein deficiency and ApoE secretion: impact on mouse plasma cholesterol levels and atherosclerosis. Arterioscler Thromb Vasc Biol 2007, 27(1):190-196.

20. Tollefson JH, Ravnik S, Albers JJ: Isolation and characterization of a phospholipid transfer protein (LTP-II) from human plasma. J Lipid Res 1988, 29(12):1593-1602.

21. Kockx M, Rye KA, Gaus K, Quinn CM, Wright J, Sloane T, Sviridov D, Fu Y, Sullivan D, Burnett JR, et al:: Apolipoprotein A-I-stimulated apolipoprotein $E$ secretion from human macrophages is independent of cholesterol efflux. J Biol Chem 2004, 279(25):25966-25977.

22. Lagrost L, Desrumaux C, Masson D, Deckert V, Gambert P: Structure and function of the plasma phospholipid transfer protein. Curr Opin Lipidol 1998, 9(3):203-209.

23. Oka T, Kujiraoka T, Ito M, Egashira T, Takahashi S, Nanjee MN, Miller NE, Metso J, Olkkonen VM, Ehnholm C, et al:: Distribution of phospholipid transfer protein in human plasma: presence of two forms of phospholipid transfer protein, one catalytically active and the other inactive. J Lipid Res 2000, 41(10):1651-1657.

24. Karkkainen M, Oka T, Olkkonen VM, Metso J, Hattori H, Jauhiainen M, Ehnholm C: Isolation and partial characterization of the inactive and 
active forms of human plasma phospholipid transfer protein (PLTP). $J$ Biol Chem 2002, 277(18):15413-15418.

25. Cheung MC, Albers JJ: Active plasma phospholipid transfer protein is associated with apoA-I- but not apoE-containing lipoproteins. J Lipid Res 2006, 47(6):1315-1321.

doi: 10.1186/1476-511X-9-59

Cite this article as: Robciuc et al., Human apoA-l increases macrophage foam cell derived PLTP activity without affecting the PLTP mass Lipids in Health and Disease 2010, 9:59

Submit your next manuscript to BioMed Centra and take full advantage of:

- Convenient online submission

- Thorough peer review

- No space constraints or color figure charges

- Immediate publication on acceptance

- Inclusion in PubMed, CAS, Scopus and Google Scholar

- Research which is freely available for redistribution

Submit your manuscript at www.biomedcentral.com/submit 